\title{
EM BUSCA DA JUSTIÇA COGNITIVA: LEITURAS E LEITORAS PARA UM PROCESSO DE ESCOLARIZAÇÃO DECOLONIAL
}

\author{
In search of cognitive justice: readings and readers for a decolonial \\ schooling process
}

\begin{abstract}
En busca de la justicia cognitiva: lecturas y lectores para un proceso de escolarización
\end{abstract}

\begin{abstract}
RESUMo Embora no plano legal, a escola como instituição e como lócus de transformação tenha podido se renovar por leis que, alterando a LDB (Lei de Diretrizes e Bases da Educação Brasileira de 1996), instituem a obrigatoriedade do ensino das histórias e culturas africanas e afro-brasileiras (Lei 10.639 de 2003), bem como, das histórias e culturas indígenas (Lei 11.645 de 2008), pode-se afirmar que no plano das relações cotidianas, subjetivas e intersubjetivas, pouco ou quase nada se alterou na educação brasileira em termos efetivos: o acesso a posições e profissões consideradas "de maior prestígio" continua figurando como privilégio atrelado ao status de reconhecida branquitude. Tal situação torna-se ainda mais nefasta quando incide a respeito do lugar e da condição dos modos e "fazeres" das mulheres negras intelectuais. Nesse sentido, este artigo pretende lançar luz sobre razões, consequências e possíveis encaminhamentos para se reverter tal quadro e promover uma ansiada descolonização epistemológica. PalaVRas-ChaVe: ANTIRRACISMO. INTELECTUAIS NEGRAS. DesColoNIZAÇÃO EPISTEMOLÓGICA.
\end{abstract}

ABSTRACT Even though in the scope of the application of law,
the school as an institution and as a locus of transformation
have been renewed by laws, that altering LDB (Law of guidelines
and basis of Brazilian education Lei - 1996), impose the obliga-
tion to teach the African and afro-brazilian cultures and history
(Law 10.639 of 2003), as well, as the indigenous culture and his-
tory (Law 11.645 of 2008), it can be affirmed that no flat every-
day, subjective and intersubjective relationships, very little or
almost nothing has changed in Brazilian education in effective
terms: access to positions and professions considered "of great-
er prestige" continues to figure as a privilege linked to the status
of recognized whiteness. Such a situation becomes all the more
damaging when it comes to the place and condition of the ways
and "doings" of black intellectual women. In this sense, this ar-
ticle intends to shed light on reasons, consequences and possible

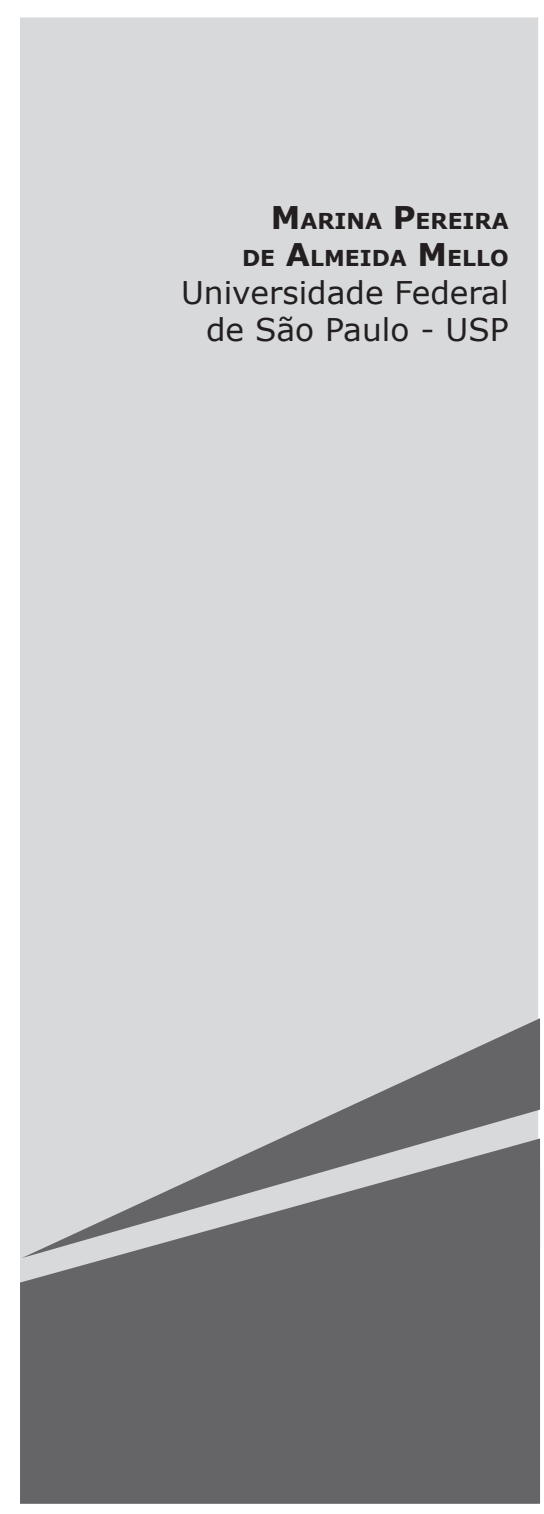


referrals to revert such a framework and promote a desired epistemological decolonization.

Keywords: Anti-racism. Black intellectuals. Epistemological decolonization.

RESUMEN Aunque en el plano legal, la escuela como institución y como locus de transformación ha podido renovarse por leyes que, alterando la LDB (Ley de Directrices y Bases de la Educación Brasileña de 1996) instituyen la obligatoriedad de la enseñanza de las historias y culturas africanas y afrobrasileñas (Ley 10.639 de 2003), así como de las historias y culturas indígenas (Ley 11.645 de 2008), se puede afirmar que en el plano de las relaciones cotidianas, subjetivas e intersubjetivas, muy poco o casi nada se alteró en la educación brasileña en términos efectivos: el acceso a posiciones y profesiones consideradas "de mayor prestigio" sigue figurando como privilegio asignado al status de reconocida branquitud. Tal situación se vuelve aún más nefasta cuando incide sobre el lugar y la condición de los modos y "haceres" de las mujeres negras intelectuales. En este sentido, este artículo pretende arrojar luz sobre razones, consecuencias y posibles encaminamientos para revertir tal cuadro y promover una ansiada descolonización epistemológica.

PALABRAS CLAVE: ANTI-RACISMO. INTELECTUALIDAD NEGRA. DESCOLONIZACIÓN EPISTEMOLÓGICA. MUJERES NEGRAS.

INTRODUÇÃO

A sobrevivência é aprender a permanecer firmes na solidão, contra a impopularidade e talvez a insultos, e aprender a fazer causa comum com outras que também estão fora do sistema e, entre todas, definir e lutar por um mundo em que todas possamos florescer. A sobrevivência está em aprender a assimilar nossas diferenças e a convertê-las em potencialidades. Porque as ferramentas do senhor nunca desmantelam a casa do senhor. Talvez nos permita obter uma vitória passageira se seguirmos as suas regras do jogo, mas nunca servirão para realizarmos uma transformação autêntica. E isso só ameaça as mulheres que ainda consideram que a casa principal é a única fonte de apoio. Audre Lorde ${ }^{1}$
Há cerca de dez anos ao resenhar o livro de Eliana de Oliveira ${ }^{2}$ que é, para mim, além de uma grande inspiração e amiga, intelectual competente e combativa, instigada pelos dados trazidos por sua investigação, comecei a delinear uma reflexão que hoje é uma das minhas principais indagações de pesquisa, qual seja: qual o papel da educação escolarizada para a transformação dos estereótipos e das expectativas (geralmente ruins) que rondam o destino de meninas e mulheres pertencentes aos estratos e categorias menos favorecidos e historicamente subalternizados, sobretudo o das mulheres negras e pobres? Outra dimensão atrelada a essa mesma questão é a tentativa de compreensão acerca do estatuto (simbólico) das intelectuais negras na conformação acadêmica e editorial brasileira.

OLIVEIRA, Eliana de. Mulher negra e professora universitária: trajetória, conflitos e identidade. Brasília: Líber Livro, 2006. 
De alguma maneira, entendo que as duas dimensões se articulam (ou deveriam se articular) na busca por respostas e se não por igualdade, pela desejável equidade na construção da escola e da academia como lócus de libertação para meninas e mulheres negras.

É evidente que as relações de poder estão, para além dos aspectos económicos, relacionados à produção eà distribuição de riqueza e de renda, inextricavelmente ligadas às questões de identidade e visibilidade, que os diversos grupos mobilizam na luta por representação. [...] Nesse sentido, o lugar social e ideológico que tem sido ocupado pelas mulheres negras corrobora e perpetua as situações históricas de menosprezo e desprezo fundadas na manutenção do status quo e, consequentemente, de identidades subalternizadas (MELLO, 2009, p. 365).

A despeito de ter escrito o texto citado há quase uma década, continuo acreditando que mesmo com alguns avanços, oriundos da mobilização dos movimentos sociais, convertidos em Políticas Públicas, a televisão e as mídias de uma maneira geral - que são poderosos instrumentos de propagação de ideias, ideais, conceitos e preconceitos - têm celebrizado imagens de mulheres negras que não rompem nem questionam os estereótipos da mulher negra para "cama e mesa". Ao contrário, tem-se naturalizado a imagem de tais mulheres transitando com desenvoltura e "naturalidade" pelos ambientes domésticos e/ou associadas a um imaginário que enfatiza uma sensualidade quase que congênita.

Embora no plano legal, a escola como instituição e como lócus de transformação tenha podido se renovar por leis que, alterando a LDB (Lei de Diretrizes e Bases da Educação Brasileira de 1996), instituem a obrigatoriedade do ensino das histórias e culturas afri- canas e afro-brasileiras (Lei 10.639 de 2003), bem como, das histórias e culturas indígenas (Lei 11.645 de 2008), pode-se afirmar que no plano das relações cotidianas, subjetivas e intersubjetivas, pouco ou quase nada se alterou na educação brasileira em termos efetivos: o acesso a posições e profissões consideradas "de maior prestígio" continua figurando como privilégio atrelado ao status de reconhecida branquitude.

Penso que tal fenômeno acontece justamente porque os paradigmas que conduzem o entendimento sobre as "diferenças" e "diferentes" se ancoram em uma cartografia de poder que prioriza sentidos ligados aos nacionalismos e colonialismos, de viés, portanto, eurocentrado e monológico: em outras palavras: capitalista, patriarcal, elitista e hierarquicamente racializado (GROSFOGUEL, 2008).

Sobretudo no Brasil, é importante destacar que um processo civilizatório de cariz assimilacionista ainda performa as mentalidades, conduzidas ao desejo pelo embranquecimento, supostamente nivelador, porquanto no plano ideológico, apagaria as diferenças. Ainda que à custa de genocídios e epistemicídios, nos gabamos por nossa "morenidade cordial".

Meneses (2009), ao cunhar o termo "justiça cognitiva", nos lembra do desafio ético representado pela ruptura de um conceito de ciência e do "científico" calcado em perspectivas monoculturais e fundamentalistas. Promover uma academia cognitivamente mais justa significa promover uma realidade em que conhecimentos ao invés de universais, sejam pluriversais e, desse modo, negociados e dialogados. Assim, ciência e técnica, ícones da racionalidade moderna não deveriam impedir a interação/tradução com/de outras e variadas práticas e saberes (MENESES, 2009, p. 234).

\section{Não ESTAR LÁ NEM CÁ MAS \\ NAS MARGENS: DESAFIANDO A \\ "COLONIALIDADE"}

Nesse percurso e na busca por um referencial teórico e metodológico que pudesse lançar luz às contradições que opõem um 
discurso de "igualdade" a uma realidade de "desigualdades", encontrei autoras que, à revelia das referências hegemônicas da produção acadêmica e intelectual, podem sinalizar caminhos alternativos para a reversão de mentalidades e comportamentos que ainda reproduzem estigmas, estereótipos, preconceitos e discriminações.

Joguem fora a abstração e o aprendizado acadêmico, as regras, o mapa e o compasso. Sintam seu caminho sem anteparos. Para alcançar mais pessoas, deve-se evocar as realidades pessoais e sociais — não através da retórica, mas com sangue, pus e suor (ANZALDÚA, 2000, p. 235).

Inicio reportando-me à feminista e teórica cultural, estadunidense de nascimento, mas "chicana" por atribuição; atribuição essa posteriormente assumida como "lugar de enunciação. Pois, em 1980, em um texto antológico denominado Carta às mulheres do terceiro mundo, ao ser convidada, segundo ela, como única mulher não branca, para integrar uma coletânea de artigos, Glória Anzaldúa produziu um texto-relato denso, forte e nem um pouco ortodoxo, revelando as agruras e dilemas que acometem uma mulher "de cor" acadêmica. ${ }^{3}$ Não uma acadêmica qualquer, mas uma mulher que a partir desse texto (embora não exclusivamente por ele), se debate a partir de sua condição marginalizada, caracterizada pela não branquitude - que de fora e do alto das certezas postas pelas vozes hegemônicas da academia - a talharam como inadequada, imprópria e deslocada.

Ao ser pois, convidada por colegas de ofício para tal empreitada, Anzaldúa percebe e anuncia as contradições e incoerências que regem a vida acadêmica e em um texto prenhe da subjetividade subalternizada, não se

O termo "acadêmica" é aqui utilizado para designar pertencimento às esferas universitárias, da pesquisa e produção de saberes nos níveis superiores de ensino e aprendizagem. constrange ao trazer à tona o processo sofrido e sempre biográfico, sempre pessoal, sempre difícil de "escrever" para um(a) outro(a) que não a enxerga, e mais do que isso, a rasura, a invisibiliza e a inscreve na condição do "não ser".

No caso em questão, Anzaldúa escolhe dirigir-se àquelas que considera seus pares: para a Outra - que ela nomeia e identifica, irmanando-se pelo epíteto mulher de cor, para estabelecer o vínculo de cumplicidade:

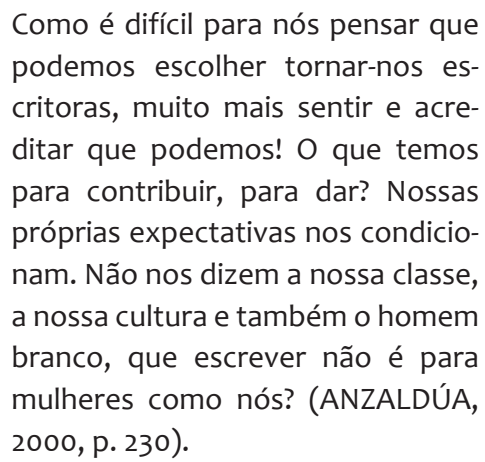

Todo texto de Anzaldúa é escrito em primeira pessoa. Ela não escreve de modo impessoal. A despeito do que apregoa a cultura acadêmica, ao não esconder quem é, imprime significados ao que faz e ao modo como o faz.

Justificando minha escolha por Anzaldúa, neste texto que se dispõe a tratar da produção intelectual de mulheres negras, parto do princípio de que não é possível nem é recomendável que se faça uma ciência limpa, íntegra ou pura, posto que, geralmente, a produção acadêmica de autoras que optam por destacar sua condição (no caso, étnico-racial) por meio da escrita, é que, como acontece com seus corpos, a forma como se manifestam torna-se alvo de estigmatização.

Penso que a academia deve buscar desancorar-se do paradigma que impinge "integridade, clareza e pureza". Justamente porque um dos conceitos a ser questionado é o da integridade, cuja busca obsessiva dá margem a todo tipo de ideologia de exclusão.

O que é um machista? Grosso modo, é aquele (ou aquela) que acha que o macho 
deve dominar impoderavelmente. O que é um racista? É alguém que acredita que os seres humanos pertencem a raças diferentes e desiguais; algo que precisamos problematizar primeiro na nossa mente e depois em nossos comportamentos. Quando eu vejo uma pessoa diferente, minha tendência é imaginar que sei de onde veio e quem é. Isso é preconceito. E os preconceitos embasam ações excludentes: discriminações.

Filha de camponeses do sul do Texas que tiveram suas famílias separadas por uma fronteira imposta, Anzaldúa, entre o fim dos anos 1950 e início dos anos 1970, teve contato com a literatura feminista. Mas é nos anos 1970 que inicia sua produção literária, quando começa a escrever peças de teatro, poemas, contos e autobiografias. Edna de Marco, tradutora brasileira do texto que me serve de base, diz: "No começo dos anos 1980, Anzaldúa passa a defender a posição de que as mulheres de cor deveriam buscar meios para expressar suas ideias, transformando-se em criadoras de suas teorias e não mais em meros objetos de estudo" (MARCO apud ANZALDÚA, 2000, p. 235).

Em Falando em línguas, texto de Anzaldúa datado de 1980, escrito nos moldes de uma carta e traduzido no Brasil somente nos anos 2000, a categoria mulheres de cor tem uma acepção que deve ser contextualizada.

Enquanto no Brasil o termo mulheres de cor se refere às mulheres de pele preta, afrodescendentes portanto; na realidade estadunidense, evocada por Anzaldúa, o termo muIheres de cor abrange todas as mulheres, cujas origens não anglo-saxônicas nem europeias as categorizam de múltiplas formas. Desse modo: asiáticas, hispânicas, afro-americanas, latino-americanas, asiático-americanas estão inscritas na categoria mulheres de cor, à revelia da cor que efetivamente apresentam e de sua autodesignação referente a seus lugares de origem. Por esse motivo, os feminismos chamados "negros" ou contra-hegemônicos, trazem como principais referências não apenas autoras afrodescendentes, como também asiáticas, latino-caribenhas, brasileiras e africanas.
Anzaldúa começa sua carta, buscando a identificação, gerada pela "imaginação", àquelas que seriam suas presumíveis leitoras, cujo cenário da ação de escrever, ela também pode muito bem imaginar, bem como, suas múltiplas condições de pertencimento ou exclusão a dadas realidades:

Queridas mulheres de cor, companheiras no escrever [...] Sento-me aqui, nua ao sol, máquina de escrever sobre as pernas, procurando imaginá-las. Mulher negra, junto a uma escrivaninha no quinto andar de algum prédio em Nova lorque. Sentada em uma varanda, no sul do Texas, uma chicana abana os mosquitos e o ar quente, tentando reacender as chamas latentes da escrita. Mulher índia, caminhando para a escola ou trabalho, lamentando a falta de tempo para tecer a escrita em sua vida. Asiático-americana, lésbica, mãe solteira, arrastada em todas as direções por crianças, amante ou ex-marido, e a escrita (ANZALDÚA, 2000, p. 229).

Anzaldúa busca, assim, estabelecer um vínculo, um elo com essa mulher que ela percebe como semelhante a si: mulher negra em Nova Iorque, mulher chicana, mulher índia, asiático-americana, lésbica, separada, amante, mãe solteira que em meio a condições inóspitas, precisa e quer escrever. E, dessa forma, a autora cria intimidade com essa proscrita que ela imagina - em sua vida cotidiana - de privações.

Não apenas identifica a mulher de cor, mas suas condições precárias de vida. Fazendo uso da emoção e da identificação com essas mulheres, ladeadas por crianças e pelo abandono, trazendo para o texto acadêmico escrevivências ${ }^{4}$ que corroborem as suas próprias:

4 Termo cunhado pela escritora brasileira Conceição Evaristo. 
Minhas queridas hermanas, os perigos que enfrentamos como mulheres de cor não são os mesmos das mulheres brancas, embora tenhamos muito em comum. Não temos muito a perder - nunca tivemos nenhum privilégio (ANZALDÚA, 2000, p. 229).

Não se trata de um mundo ideal; trata-se de trazer à tona um mundo apagado, escondido, colocado geralmente debaixo do tapete por quem escreve a partir da perspectiva da academia.

É improvável que tenhamos amigos nos postos da alta literatura. A mulher de cor iniciante é invisível no mundo dominante dos homens brancos e no mundo feminista das mulheres brancas, apesar de que, neste último, isto esteja gradualmente mudando. A lésbica de cor não é somente invisível, ela não existe. Nosso discurso também não é ouvido. Nós falamos em línguas, como os proscritos e os loucos. Porque os olhos brancos não querem nos conhecer, eles não se preocupam em aprender nossa língua, a língua que nos reflete, a nossa cultura, o nosso espírito. As escolas que frequentamos, ou não frequentamos, não nos ensinaram a escrever, nem nos deram a certeza de que estávamos corretas em usar nossa linguagem marcada pela classe e pela etnia (ANZALDÚA, 2000, p. 229).

Anzaldúa busca, assim, identificar a cumplicidade com a mulher que, proscrita por sua linguagem, sua etnia e/ou sua classe, em meio a condições precárias e estigmatizantes, precisa e quer escrever pois, por esse modo, alguma compreensão de si e do mundo pode se concretizar. Concretizar talvez não seja o verbo mais adequado para dar conta das ex- periências de mulheres para quem o próprio ato de existir se configura como transgressor. Para além de tornar seu mundo concreto, o que elas anseiam é se tornarem sujeitos e, desse modo, mais do que concretude, temos subjetividades.

Ao buscar identificar sua interlocutora não apenas pela cor ou raça, mas por suas condições precárias de vida, faz uso da emoção e do afeto que a liga a tais mulheres, ladeadas por crianças e pelo abandono.

Assim, Anzaldúa encena uma performance - em que os textos surgem a partir de fragmentos e papéis soltos, escritos produzidos nos lugares e tempos mais improváveis: no vaso do banheiro, com o barulho das pessoas que habitam a casa, com as cores, sons e sabores que norteiam e habitam seu cotidiano: imprevisível e imponderável, assim como sua escrita.

O homem branco diz: Talvez se rasparem o moreno de suas faces. Talvez se branquearem seus ossos. Parem de falar em línguas, parem de escrever com a mão esquerda. Não cultivem suas peles coloridas, nem suas línguas de fogo se quiserem prosperar em um mundo destro. O homem, como os outros animais, tem medo e é repelido pelo que ele não entende, e uma simples diferença é capaz de conotar algo maligno (ANZALDÚA, 2000, p. 230).

O homem branco diz, o homem branco nomeia, o homem branco define: o que pode, o que não pode, o que é, o que não é. A colonialidade, intrinsecamente generificada e racializada determina, sob a cruzada "civilizatória" quem é humano e quem, por sua vez, não sendo homem, nem branco nem cristão, não é gente, tampouco humano (LUGONES, 2008).

Nós fomos moldadas como uma imagem perfeita em tudo o que se refere ao doméstico, artístico, ser- 
vil, fomos consideradas "especialistas em sexo". É assim que foi nutrido o preconceito de que a mulher negra só serve para esses propósitos. [...]. Um ditado "popular" brasileiro sintetiza essa situação, afirmando: "Branca para casar, mulata para fornicar, preta para trabalhar". Que se atente aos papéis atribuídos às amefricanas (pretas e mulatas); abolida sua humanidade, elas são vistas como corpos animalizados: por um lado são os "burros de carga" do sexo (dos quais as mulatas brasileiras são um modelo). Desta forma, podemos ver como a super-exploração socioeconômica se alinha à super-exploração sexual das mulheres amefricanas (GONZALEZ, 1988, p. 4).

Desse modo, nenhuma mulher é humana. Mas, sendo a mulher "branca" a progenitora por excelência da raça eleita, caberá às outras mulheres o lugar animalizado e selvagem de tudo que venha a fazer ou desejar: seu trabalho, seu corpo, seu sexo: representam por essa racionalidade: o outro lado, o lado escuro e incerto, primitivo e perigoso das proscritas.

Por que eles nos combatem? Por que pensam que somos monstros perigosos? Por que somos monstros perigosos? Porque desequilibramos e muitas vezes rompemos as confortáveis imagens estereotipadas que os brancos têm de nós: A negra doméstica, a pesada ama de leite com uma dúzia de crianças sugando seus seios, a chinesa de olhos puxados e mão hábil — "Ela sabe, de cara achatada, passivamente deitada de costas, sendo comida pelo homem a la La Chingada, como tratar um homem na cama" -, a chicana ou a índia (ANZALDÚA, 2000, p. 231).
Vencer pois, o estigma da domesticidade congênita é um desafio para as intelectuais negras, que não podendo se furtar aos estereótipos que a alteridade subalternizada lhes impõe, encenam, por vezes, performances em que as condições de deslocamento e incômodo vêm à tona.

O mundo visto e escrito por esse viés não é, portanto, ideal e, como tal, não é organizado, tampouco docilizado; trata-se de trazer à luz um mundo apagado, escondido, colocado geralmente debaixo do tapete. Anzaldúa, Lugones e Gonzalez entre ouras, o trazem para dentro da academia.

Segundo Anzaldúa, assim como os loucos e proscritos, nós - mulheres de cor - falamos em "línguas": de um modo truncado e tosco, desagradável, pouco polido.

Porém, não são raras as vezes em que a mímese acontece - entendida aqui não como cópia, mas pela acepção de Homi Bhabha (1998) - ou seja, a repetição com diferença differánce - que não sendo arremedo do original, representa a repetição do Outro a partir de um outro lócus de enunciação e, portanto, com ousadia e criatividade.

Da produção intelectual de tais mulheres emergem sentimentos de raiva, frustração, ressentimento. Geralmente, sua mensagem não é limpa nem agradável. Elas denunciam as espoliações que sofreram.

Vivendo numa sociedade fundamen-
talmente anti-intelectual é dificil
para os intelectuais comprometidos
e preocupados com mudanças so-
ciais radicais afirmar sempre que o
trabalho que fazemos tem impacto
significativo. Nos círculos políticos
progressistas o trabalho dos inte-
lectuais raramente é reconhecido
como uma forma de ativismo; na
verdade expressões mais visíveis
de ativismo concreto (como fazer
piquetes nas ruas ou viajar para um
país do Terceiro Mundo e outros
atos de contestação e resistência)
são consideradas mais importantes 
para a luta revolucionaria que o trabalho mental (HOOKS, 1995, p. 464).

A clássica oposição entre trabalho manual e trabalho mental traduz, portanto, um efeito da colonialidade (dicotomicamente racializada) em que caberia a sujeitos hierarquicamente inferiores agir e resistir apenas pela emoção, pelos instintos em que, supostamente, a carência de "razão" os alinharia ao plano da natureza animalizada (selvagem e indômita).

É essa desvalorização do trabalho intelectual que muitas vezes torna difícil para indivíduos que vêm de grupos marginalizados, considerarem importante $\mathrm{O}$ trabalho intelectual, uma atividade útil. Ao longo de nossa história como afro americanos nos Estados Unidos surgiram intelectuais negros de todas as classes e camadas da vida. Contudo a decisão de trilhar conscientemente um caminho intelectual foi sempre uma opção excepcional e difícil. Para muitos de nós tem parecido mais um chamado que uma escolha vocacional. Somos impelidos, até mesmo empurrados para o trabalho intelectual por forças mais poderosas que a vontade individual (HOOKS, 1995, p. 465).

Quando revelada, a vulnerabilidade pode ser traduzida como fraqueza. É o que sugere o senso comum. A estratégia de Anzaldúa, ao revelar suas fragilidades é, ao contrário, promover a identificação com as outras: também fracionadas e frágeis, que por essa via, podem se encontrar e se fortalecer.

\section{ConsideraÇões Finais}

\section{DA NECESSIDADE DE IMPLODIR OS}

\section{ESSENCIALISMOS}

Ao abordar a questão do deslocamento, é praticamente impossível não evocar Franz
Fanon (2008) e sua correlata angústia para identificar e traduzir as sensações que acometem os seres fendidos - de fora para dentro. As ambiguidades nos fendem a todos, mas para alguns é dado o beneplácito da integridade, da pureza e da legitimidade.

Dado que a condição do subalterno é o silêncio e a invisibilidade, a insurgência promovida pela escolha da escrita como forma de desejar e pensar o mundo, transmitindo vivências e experiências por meio da palavra escrita, nos leva à categoria da colonialidade de gênero e seu consequente corolário: a decolonialidade de gênero proposta por Maria Lugones (2008).

Entre outras possibilidades, o conceito postula articular a diferença a partir de outro lócus, que possa, de algum modo, implodir os essencialismos que associam de maneira incondicional a natureza à cultura.

[...] podemos afirmar que o decolonial como rede de pesquisadores que busca sistematizar conceitos e categorias interpretativas tem uma existência bastante recente. [...] a decolonialidade consiste também numa prática de oposição e intervenção, que surgiu no momento em que o primeiro sujeito colonial do sistema mundo moderno/colonial reagiu contra os desígnios imperiais que se iniciou em 1492. Sem utilizar precisamente o termo "colonialidade", já era possível encontrarmos a ideia que gira em torno desse conceito em toda a tradição do pensamento negro. A título de exemplo, podemos encontrar contemporaneamente essa ideia em autores e autoras tais como W. E. B. Du Bois, Oliver Cox, Frantz Fanon, Cedric Robinson, Aimé Césaire, Eric Williams, Angela Davis, Zora Neale Huston, Bell Hooks etc. Entretanto, a articulação desta ideia - já identificada com o conceito de colonialidade - foi formulada de maneira explícita por Immanuel 
Wallerstein (1992). Na sequência, o conceito de Wallerstein foi retomado por Anibal Quijano, que passou a nomeá-lo como colonialidade do poder (BERNARDINO \& GROSFOGUEL, 2016, p. 17).

Lugones (1998), ao problematizar as dicotomias hierárquicas (preto/branco, homem/mulher, macho/fêmea) legadas pela racionalidade moderna, cartesiana e capitalista, assinala outras possibilidades para o entendimento das diferenças e, nesse sentido, para a superação das desigualdades assentadas nessa compreensão dos fenômenos.

A distinção entre comportamentos, coisas e lugares que são de homem, comportamentos, coisas e lugares que são de mulher, ou de pretos ou de brancos, foi artificialmente construída, a partir de uma estrutura de poder que precisamos conhecer para questionar. Uma estrutura que deve ser problematizada porque nada tem de natural e precisamos entender que o fato de que a condição de gênero seja condicionada pelos papéis sexuais e sexuados, não é absoluta nem universal.

Isso porque a partir desse ponto de vista, várias e outras maneiras de estar no mundo, tanto sexuais quanto de gênero foram desautorizadas e tachadas de anormais, selvagens, primitivas; adjetivos que desumanizam seres, processos e cosmovisões.

Desse modo, Anzaldúa, embora seja uma acadêmica no sentido lato do termo, não o é no sentido estrito. Usa como estilo de escrita não uma escrita dura, mas aquela que também traz à superfície o que deveria permanecer no âmbito do escondido, do guardado, do recalcado. Assim, a escrita acadêmica que deveria estar isenta de sentimento, sendo o mais objetiva possível, invoca questões existenciais que são, para além de meramente individuais ou particulares, coletivas.

Será que isso é possível?

Será que na escrita de qualquer produção acadêmica não permanecem ali traços da vida vivida? Não haveria ali evidências do que foi vivido, das respectivas visões de mundo, espiritualidades? Escolhas, pontos de vista diante das pessoas e das coisas não estariam expostos?

Uma das características da literatura produzida por Anzaldúa (2000), Hooks (1995) e Gonzalez (2008) é o tom confessional. São obras produzidas ali, no cotidiano, a partir das vivências, da imaginação, do que anseiam e desejam para si e para o mundo em que habitam.

Quanto da produção dessas mulheres é autorizada? Qual é a posição que elas ocupam em uma realidade em que alguns são autorizados e outros são recorrentemente desqualificados e subalternizados?

Quem está no lugar? E quem define os lugares de autoridade e de obediência?

$\mathrm{Na}$ perspectiva aqui contemplada, as autoras, ao projetarem por sua escrita a condição de não serem vistas nem como mulheres, nem como intelectuais, fazem irromper as fissuras entre os feminismos tradicionais e os feminismos contra-hegemônicos, ao mesmo tempo em que promovem o questionamento das referências a respeito do que seja homem, humano, mulher, família, sexualidade. Tratar de maneiras diferentes de estar no mundo também implica em considerar formas diferentes de se manifestar diante (de) e para o mundo e, portanto, de escrever.

Por fim e ao termo, é importante retomar o conceito de "justiça cognitiva" que, em suma, diz respeito às possibilidades de existir e resistir para além das fronteiras implicadas pelo capitalismo, colonialismo e patriarcado, que impingem indignidade às existências femininas não autorizadas. Na medida em que a presença e a existência cotidiana e renitente dessas e de outras mulheres se revestem do desejo e do movimento de re-existir a despeito do modelo epistêmico moderno-ocidental, tece-se uma realidade menos excludente, menos perversa.

A academia em sentido strictu e a escola em sentido latu devem propiciar os espaços-tempos para a transformação das referências para pensar e praticar um mundo mais justo desde sua pluriversalidade. 


\section{REFERÊNCIAS}

ANZALDÚA, Gloria. Falando em línguas: uma carta para as mulheres escritoras do terceiro mundo. Santa Catarina: Revista de Estudos Feministas (UFSC), p. 229-236, jan. 2000.

BERNARDINO-COSTA, Joaze; GROSFOGUEL, Ramón. Decolonialidade e perspectiva negra. Revista Sociedade e Estado. Brasília, v. 31, n. 1, p. 15-24, jan./abr. 2016.

BHABHA, Homi K. O local da cultura. Belo Horizonte: Ed. UFMG, 1998.

BUTLER, Judith; ANASTASIOU, Athena. Dispossession: The performative in the political. Cambridge: Polity, 2013.

COLLINS, Patricia Hill. Black Feminist Thought: Knowledge, Consciousness and the Politics of Empowermen. Londres: Routledge, 2000.

COLLINS, Patricia Hill. Aprendendo com a outsider within: a significação sociológica do pensamento feminista negro. Revista Sociedade e Estado. Brasília, v. 31, n. 1, p. 99-127, jan./abr. 2016.

FANON, Frantz. Pele negra, máscaras brancas. Salvador: EDUFBA, 2008.

GOMES, Nilma L. Relações étnico-raciais, educação e descolonização dos currículos. Currículo sem Fronteiras, v. 12, n. 1, p. 98-109, 2012.

GONZALEZ, Lélia. Racismo e Sexismo. Revista Crítica de Ciências Sociais, v. 80, p. 115-147, mar. 2008.

GROSFOGUEL, Ramon. Para descolonizar os estudos de economia política e os estudos pós-coloniais: Transmodernidade, pensamento de fronteira e colonialidade global. Revista Crítica de Ciências Sociais, v. 80, p. 115-147, mar. 2008.

HOOKS, Bell. Intelectuais Negras. Estudos Feministas. Ano 3, p. 2-95, 1995.

LORDE, Audre. La Hermana, la extranjera. Madri: Horas y Horas, 2003.

LUGONES, Maria. Colonialidade e gênero. Bogotá-Colômbia: RevistaTabula Rasa. Num. 9, p. 73-101, jul./dez. 2008.

MELLO, Marina P. A. Nem Tia Nastácia nem Globeleza... Vamos levar as mulheres negras para as salas? Revista Sociedade e Cultura, Goiânia, v. 12, n. 2, p. 365-366, jul./dez. 2009.

SANTOS, Boaventura de Sousa. "Para além do pensamento abissal: das linhas globais a uma ecologia de saberes." In: Boaventura de Sousa Santos e Maria Paula Meneses (Orgs.), Epistemologias do Sul. Coimbra: Almedina/CES, p. 23-71, 2009.

YOUNG, Michael. ¿Por qué deben los educadores diferenciar entre conocimiento y experiencia?, Fermentario, n. 9, v. 1, p. 1-19, 2015.

Submetido em: 23-8-20-18

Aceito em: 12-4-2019 